\title{
Rebound adrenal insufficiency after withdrawal of ritonavir in a 65-year-old man using inhaled budesonide
}

\author{
Olivier Veilleux MD, Todd C. Lee MD MPH, Emily G. McDonald MD MSC
}

Cite as: CMAJ 2017 September 18;189:E1188-91. doi: 10.1503/cmaj.170415

A 65-year-old man with a 14-year history of well-controlled HIV infection presented to the emergency department with three weeks of nausea, abdominal pain and confusion. His medical history included chronic obstructive pulmonary disease with features of asthma and infrequent exacerbations, allergic rhinitis, hypertension, dyslipidemia, chronic kidney disease (estimated glomerular filtration rate [eGFR] $30 \mathrm{~mL} / \mathrm{min} / \mathrm{m}^{2}$ ), osteopenia, gastresophageal reflux disease, and a remote history of depression. His viral load had been undetectable, with a CD4 count above 400 (normal range 356-1573) cells $/ \mu \mathrm{L}$ for many years on a ritonavir-containing antiretroviral regimen. He was also taking intranasal budesonide (total daily dose $128 \mu \mathrm{g}$ ), as well as inhaled budesonide (total daily dose $800 \mu \mathrm{g}$ ) in combination with formoterol. In response to a decline in his bone mineral density, recent progressive renal dysfunction (eGFR had decreased from 60 to $30 \mathrm{~mL} / \mathrm{min} / \mathrm{m}^{2}$ over the course of the year) and worsening dyslipidemia, his antiretroviral therapy was changed to abacavir, lamivudine and dolutegravir eight weeks before he presented to the emergency department.

Following this change in treatment, the patient was seen in the chronic viral illness clinic, and he reported asthenia, anorexia, nausea and intermittent episodes of crampy epigastric abdominal pain. He was afebrile, his seated blood pressure was $110 / 70 \mathrm{~mm} \mathrm{Hg}$, with a pulse rate at 100 beats $/ \mathrm{min}$. The remainder of the physical exam was unremarkable. A contrast-enhanced computed tomography (CT) scan of the abdomen did not show a cause for his abdominal pain.

The patient's new antiretroviral regimen was put on hold, and genetic testing for a predisposition to abacavir hypersensitivity was conducted as a possible explanation for his symptoms. Because the patient was volume depleted, treatment with intravenous saline was started. After receiving $3 \mathrm{~L}$ of crystalloid, he felt better and was discharged home, with all antiretroviral treatments suspended and follow-up scheduled in clinic.

Two weeks after discharge, the patient presented to the emergency department. In addition to intermittent epigastric pain, he now reported five days of headache, worsening fatigue, diffuse arthralgias, myalgias and fever. His wife also reported that he had been having difficulty with difficulty with planning and organizing his daily tasks, short-term memory and finding words. Upon physical examination, his body temperature was $38.9^{\circ} \mathrm{C}$, and he had sinus tachycardia of

\section{KEY POINTS}

- Deprescribing should be encouraged and the use of a systematic approach that includes, as a final step, careful monitoring following drug discontinuation may help minimize the risk of adverse drug effects.

- The possibility of drug interactions should be considered when medications are prescribed in combination but also during deprescribing.

- When it comes to stopping strong cytochrome inducers or inhibitors, clinicians should be aware that this may affect the levels of substrate drugs that are coprescribed.

- Prior to prescribing strong inducers or inhibitors of cytochromes, physicians should consider the downstream effects that may occur if the drug is discontinued. Choosing an alternate drug may prevent the need for close monitoring when deprescribing.

110 beats/min and a blood pressure of $100 / 60 \mathrm{~mm} \mathrm{Hg}$, which fell to $90 / 50 \mathrm{~mm} \mathrm{Hg}$ after one minute of standing. Jugular venous pressure was $0 \mathrm{~cm}$ above the sternal angle. The remainder of the physical examination was normal. His Montreal Cognitive Assessment was $14 / 30$, indicating substantially impaired cognitive function.

The patient had a CD4 count of 350 cells/ $\mu \mathrm{L}$, and his plasma HIV RNA level had risen from previously undetectable to 1.5 million copies/mL. A plain CT scan of his head was unremarkable. A lumbar puncture was performed and showed an isolated lymphocytic pleocytosis without other biochemical abnormalities. Although further testing excluded bacterial, non-HIV viral and fungal infections, he was given empiric treatment with piperacillin-tazobactam.

Results of multiple tests for infectious causes were negative. As part of a work-up for endocrine causes, we ordered a morning cortisol, which was 30 (normal range 120-535) nmol/L. Given the patient's long-term high-dose exposure to inhaled and nasal corticosteroids in conjunction with recent discontinuation of ritonavir, we suspected a diagnosis of adrenal insufficiency, and an intramuscular adrenocorticotropic hormone (ACTH, $250 \mu \mathrm{g})$ stimulation test was performed. Cortisol levels at 30 minutes increased to $65 \mathrm{nmol} / \mathrm{L}$ and at $60 \mathrm{~min}$ utes to $340 \mathrm{nmol} / \mathrm{L}$. This response was less than expected and was diagnostic of adrenal insufficiency. After 72 hours of intravenous 
hydrocortisone, we started the patient on oral replacement doses of hydrocortisone (15 mg in the morning and $10 \mathrm{mg}$ at night), with resolution of fever and abdominal pain, and a return to his baseline cognitive function. Intranasal corticosteroids were stopped and inhaled corticosteroids were reduced to a total daily dose of $200 \mu \mathrm{g}$.

\section{Discussion}

In this illustrative case, adrenal insufficiency developed in our patient when ritonavir, a potent inhibitor of the cytochrome P450 (CYP) 3A4 pathway, was withdrawn. Ritonavir inhibited the metabolism of budesonide, a substrate of the CYP3A4 enzyme. When taken concurrently, this combination of drugs resulted in increased plasma concentration of budesonide and suppression of the adrenal axis. ${ }^{1}$ This interaction has been described with both oral and inhaled corticosteroids.

Box 1: Common cytochrome P450 inducers, inhibitors and substrates*, $†$

\begin{tabular}{|c|c|c|c|}
\hline Cytochrome P450 & Common inducers & Common inhibitors & Common substrates \\
\hline 2D6 & $\begin{array}{l}\text { - Rifampin } \\
\text { - Dexamethasone }\end{array}$ & $\begin{array}{l}\text { - Bupropion } \\
\text { - Paroxetine } \\
\text { - Fluoxetine } \\
\text { - Cimetidine }\end{array}$ & $\begin{array}{l}\text { - Carvedilol } \\
\text { - Codeine } \\
\text { - Risperidone } \\
\text { - Donepezil } \\
\text { - Tricylic } \\
\text { antidepressants (e.g., } \\
\text { amitriptyline) }\end{array}$ \\
\hline 2B6 & $\begin{array}{l}\text { - Carbamazepine } \\
\text { - Phenobarbital } \\
\text { - Phenytoin } \\
\text { - Rifampin } \\
\text { - Efavirenz }\end{array}$ & - NA & - Methadone \\
\hline $1 \mathrm{~A} 2$ & $\begin{array}{l}\text { - Carbamazepine } \\
\text { - Insulin } \\
\text { - (Es)omeprazole }\end{array}$ & $\begin{array}{l}\text { - Fluvoxamine } \\
\text { - Fluoxetine } \\
\text { - Cimetidine }\end{array}$ & $\begin{array}{l}\text { - Warfarin } \\
\text { - Propranolol } \\
\text { - Olanzapine }\end{array}$ \\
\hline $3 \mathrm{~A} 4$ & $\begin{array}{l}\text { - Efavirenz } \\
\text { - Pioglitazone }\end{array}$ & $\begin{array}{l}\text { - Verapamil } \\
\text { - Diltiazem } \\
\text { - Ritonavir }\end{array}$ & $\begin{array}{l}\text { - Alprazolam } \\
\text { - Tacrolimus } \\
\text { - Simvastatin, } \\
\text { atorvastatin, lovastatin } \\
\text { (NOT rosuvastatin, } \\
\text { NOT pravastatin) } \\
\text { - Amlodipine } \\
\text { - Fentanyl } \\
\text { - Cyclosporine } \\
\text { - Apixaban } \\
\text { - Rivaroxaban }\end{array}$ \\
\hline $2 \mathrm{C9}$ & $\begin{array}{l}\text { - Carbamazepine } \\
\text { - St. John's wort }\end{array}$ & - Amiodarone & $\begin{array}{l}\text { - Sulfonylureas } \\
\text { - Losartan } \\
\text { - Irbesartan } \\
\text { - Warfarin }\end{array}$ \\
\hline $2 \mathrm{C} 19$ & $\begin{array}{l}\text { - Carbamazepine } \\
\text { - St. John's wort } \\
\text { - Efavirenz }\end{array}$ & $\begin{array}{l}\text { - Lansoprazole } \\
\text { - (Es)omeprazole }\end{array}$ & - Clopidogrel \\
\hline $2 C 8$ & - NA & - Gemfibrozil & - Repaglinide \\
\hline
\end{tabular}

Note: FDA = Food and Drug Administration, NA = not applicable.

${ }^{*}$ For a complete list see the P450 Interaction table, ${ }^{7}$ Foisy and colleagues, ${ }^{8}$ and Table $2-2$ of the US FDA report "Drug Development and Drug Interactions: Table of Substrates, Inhibitors and Inducers." ${ }^{9}$

tWhen an inducer is stopped, metabolism of the substrate drug decreases and the plasma concentration increases. When an inhibitor is stopped, metabolism of the substrate drug increases and the plasma concentration decreases.
While our patient was taking ritonavir, he had suppressed metabolism of budesonide, and the resulting higher physiologic levels of budesonide led to suppression of ACTH and cortisol synthesis. When ritonavir was stopped, a sudden decrease in budesonide occurred through increased metabolism. With antiretroviral treatment suspended, the patient's HIV viral load rose rapidly, and in the setting of a suppressed $\mathrm{ACTH}$, this rise precipitated an adrenal crisis. The patient's presenting symptoms (vague abdominal pain, fatigue, general malaise and weight loss) were most likely caused by adrenal insufficiency. Fever and confusion may have been secondary to both adrenal insufficiency and a rapid rise in HIV viral load. His symptoms resolved rapidly with physiologic doses of corticosteroid replacement, before we reinstituted highly active retroviral therapy. It should be noted that we were unable to determine the patient's adherence to the prescribed budesonide dosage and that we did not obtain plasma budesonide levels; there may be alternate explanations for this patient's clinical course.

There have been numerous reports of iatrogenic Cushing syndrome in patients receiving concomitant oral or inhaled corticosteroids in both the presence and absence of ritonavir. A literature search by Wood and colleagues in 2015 identified 51 published cases of adverse events that occurred when protease inhibitors were used in combination with inhaled or intranasal corticosteroids. ${ }^{2}$ Fluticasone exhibits the most suppressive effect on the hypothalamic pituitary axis; ${ }^{3}$ however, most inhaled steroids can suppress the axis, and the use of budesonide with ritonavir is not recommended in the US guidelines for HIV treatment. ${ }^{4}$

To date, drug interactions are most often considered when two or more drugs are prescribed together. In recent years, in response to polypharmacy (the concurrent use of five or more drugs), there has been greater interest in stopping unnecessary drugs or minimizing the number of prescribed drugs through a process called deprescribing. Although the concept is not new, the term was first introduced in 2003 and involves the evaluation of risks and benefits of specific drugs with the aim of stopping or reducing them, while taking into consideration the patient's biopsychosocial context. ${ }^{5}$

There are several frameworks for deprescribing; one systematic stepwise approach was proposed by Scott and colleagues in $2015 .{ }^{6}$ Their five-step process starts with a review of all drugs being taken by a patient and establishing the specific indication; the potential for druginduced harm; setting a priority list for 
deprescribing; and, finally, establishing a system to monitor and detect adverse effects related to withdrawal of the drug.

In this case, we highlight a less common and less recognized adverse effect of deprescribing drugs: that cessation of one drug might result in changes in the metabolism of another, either increasing or decreasing its potency or effectiveness. Stopping a drug that is an inducer or inhibitor of the cytochrome P450 pathway can result in inadvertent adverse drug events related to altered metabolism of certain substrate drugs of enzyme complexes. This phenomenon is especially true for patients who have been in a relative "homeostasis" on multiple interacting drugs for an extended time. Some adverse events caused by cessation of a drug are predictable and potentially avoidable or ameliorable with improved knowledge of pharmacokinetics. The most harmful of these will occur when a substrate drug with a narrow therapeutic index (e.g., warfarin) is affected.

As an example, consider a patient taking St. John's wort (an inducer of CYP2C9) and warfarin (a CYP2C9 substrate). There is a potential for an adverse event when the patient stops taking St. John's wort. The substrate drug (warfarin) will accumulate and increase the risk of supratherapeutic international normalized ratio and bleeding events.

There are only a few relevant inhibitors and inducers that patients take on a long-term basis that may be affected by deprescribing, along with a limited number of substrates with narrow enough therapeutic windows that harm may result if their metabolism is suddenly altered. Box 1 lists examples of drugs that are inducers or inhibitors of the P450 pathway and tend to be prescribed long term, and the

Box 2: Theoretical clinical situations where deprescribing could lead to an adverse drug event and how to prevent or ameliorate this effect ${ }^{7-9}$

\begin{tabular}{lll}
$\begin{array}{l}\text { Drug for } \\
\text { deprescription }\end{array}$ & Substrate & $\begin{array}{c}\text { Possible adverse drug reaction from } \\
\text { stopping an enzyme inducer or inhibitor }\end{array}$ \\
\hline $\begin{array}{l}\text { Ritonavir } \\
\text { (Strong inhibitor) }\end{array}$ & $\begin{array}{l}\text { Fluticasone, } \\
\text { budesonide }\end{array}$ & $\begin{array}{l}\text { Decreased level of corticosteroids } \rightarrow \text { adrenal } \\
\text { insufficiency }\end{array}$ \\
\hline
\end{tabular}

Pioglitazone Decreased level of pioglitazone $\rightarrow$ hyperglycemia

Candesartan Increased level of candesartan $\rightarrow$ hypotension or acute kidney injury

\section{Phenytoin}

(Strong inducer)

Simvastatin

Increased level of simvastatin $\rightarrow$ rhabdomyolysis, acute liver injury

\section{Carbamazepine}

(Strong inducer) rivaroxaban

Fluoxetine, paroxetine, Repaglinide bupropion

(Strong inhibitors)

Gemfibrozil

(Inhibitor)

Verapamil, diltiazem Fentanyl

(Inhibitors)

St. John's wort

(Inducer)
Olanzapine

Cyclosporine

Apixaban,

Increased therapeutic effect of apixaban or rivaroxaban $\rightarrow$ bleeding events

Propranolol Increased level of propranolol $\rightarrow$ bradycardia

Increased level of olanzapine $\rightarrow$ increased sedative effect, orthostatism, extrapyramidal effects

Increased level of cyclosporine $\rightarrow$ risk of acute calcineurin inhibitor nephrotoxicity

Decreased level of repaglinide $\rightarrow$ hyperglycemia

Repaglinide

Decreased level of repaglinide $\rightarrow$ hyperglycemia

Decreased level of fentanyl $\rightarrow$ pain crisis

Warfarin
Increased level of warfarin $\rightarrow$ supratherapeutic INR and bleeding events
Prevention or amelioration of potential rebound adverse drug event

Monitor for signs and symptoms of adrenal insufficiency; perform an ACTH stimulation test if symptoms of adrenal insufficiency present; depending on symptoms and duration of adrenal axis suppression, supplemental cortisone may be required

Monitor for glycemia; increase pioglitazone if symptomatic hyperglycemia develops or switch to an alternative agent

Monitor blood pressure and renal function; decrease dose of candesartan if blood pressure decreases or creatinine increases

Monitor for symptoms of myalgia and weakness; monitor for symptoms of right upper quadrant pain and jaundice; decrease dose of simvastatin or stop drug if adverse effects occur

Monitor for adverse effects and decrease dose of olanzapine

Monitor renal function and electrolytes; consult transplant service to adjust cyclosporine if toxicity develops

Monitor for signs of bleeding; counsel patient to seek medical attention if bleeding complication occurs

Monitor for bradycardia/arrhythmia and adjust dose

Monitor for hyperglycemia; increase dose of repaglinide or add a second agent if symptomatic hyperglycemia develops

Monitor for hyperglycemia; increase dose of repaglinide if symptomatic hyperglycemia develops

Monitor for symptoms of pain crisis; counsel patient to seek medical attention if symptoms of opioid withdrawal develop

Monitor INR more frequently; decrease warfarin dose

Note: $\mathrm{ACTH}=$ adrenocorticotropic hormone, INR = international normalized ratio.

${ }^{*}$ Important concept: patients taking multiple drugs can be in a state of relative homeostasis. Clinicians should be aware that stopping a strong inducer or inhibitor may affect the metabolism of some substrate drugs, whether increasing (inducer stopped) or decreasing (inhibitor stopped) their therapeutic effect. 
relevant substrates that may result in harm secondary to altered metabolism. Examples of clinical scenarios where rebound adverse drug events may occur when drugs are stopped and how to avoid or ameliorate them are listed in Box 2.

As polypharmacy becomes increasingly common, a systematic approach to deprescribing that includes monitoring for effects directly related to stopping a drug and a better appreciation for pharmacokinetics will lead to greater awareness for these types of interactions and minimize the risk of adverse drug events.

\section{References}

1. Kedem E, Shahar E, Hassoun G, et al. Iatrogenic Cushing's syndrome due to coadministration of ritonavir and inhaled budesonide in an asthmatic human immunodeficiency virus infected patient. J Asthma 2010;47:830-1.

2. Wood BR, Lacy JM, Johnston C, et al. Adrenal insufficiency as a result of ritonavir and exogenous steroid exposure: report of 6 cases and recommendation for management. J Int Assoc Provid AIDS Care 2015;14:300-5.

3. Lipworth BJ. Systemic adverse effects of inhaled corticosteroid therapy: a systematic review and meta-analysis. Arch Intern Med 1999;159:941-55.

4. Panel on Antiretroviral Guidelines for Adults and Adolescents. Guidelines for the use of antiretroviral agents in HIV-1-infected adults and adolescents. Washington: Department of Health and Human Services; 2016. Available: www.aidsinfo.nih.gov/ContentFiles/AdultandAdolescentGL.pdf (accessed 2017 Feb. 2).

5. Woodward MC. Deprescribing: achieving better health outcomes for older people through reducing medications. J Pharm Pract Res 2003;33:323-8.

6. Scott IA, Hilmer SN, Reeve E, et al. Reducing inappropriate polypharmacy: the process of deprescribing. JAMA Intern Med 2015;175:827-34.
7. P450 Drug interaction table. Indianapolis (IN): Indiana University; 2016. Available: http://medicine.iupui.edu/clinpharm/ddis/main-table (accessed 2017 Feb. 3).

8. Foisy MM, Yakiwchuk EM, Chiu I, et al. Adrenal suppression and Cushing's syndrome secondary to an interaction between ritonavir and fluticasone: a review of the literature. HIV Med 2008;9:389-96.

9. Drug development and drug interactions: table of substrates, inhibitors and inducers (Table 2-2). Silver Spring (MD): US Food and Drug Administration; 2016. Available: https://www.fda.gov/drugs/developmentapprovalprocess/ developmentresources/druginteractionslabeling/ucm093664.htm (accessed 2017 Mar. 10)

\section{Competing interests: None declared.}

This article has been peer reviewed.

The authors have obtained patient consent.

Affiliations: Department of Medicine (Veilleux, Lee, McDonald), McGill University; Clinical Practice Assessment Unit (Lee, McDonald), McGill University Health Centre, Montréal, Que.

Contributors: All of the authors contributed to development of the study concept and design, conduct of the analyses and interpretation of the results. All of the authors participated in drafting the manuscript and revising it critically for important intellectual content, gave final approval of the version to be published and agreed to be accountable for all aspects of the work.

Correspondence to: Emily McDonald, emily.mcdonald@mcgill.ca 